\title{
Influence of static strength on the fatigue resistance of welds
}

\author{
Ceferino Steimbreger ${ }^{1, *}$, Nenad Gubeljak ${ }^{2}$, Norbert Enzinger ${ }^{3}$, Wolfgang Ernst ${ }^{4}$, and Mirco Chapetti $^{1}$ \\ ${ }^{1}$ Laboratory of Experimental Mechanics (LABMEX), INTEMA (Institute for Material Science and Technology), CONICET - University \\ of Mar del Plata, J.B. Justo 4302 (B7608FDQ), Mar del Plata, Argentina \\ ${ }^{2}$ Faculty of Mechanical Engineering, University of Maribor, Slovenia \\ ${ }^{3}$ Institute for Materials Science and Welding, Graz University of Technology, Kopernikusg. 24 (8010), Graz, Austria \\ ${ }^{4}$ Voestalpine Stahl GmbH, Linz, Austria
}

\begin{abstract}
The present paper deals with a fracture mechanic approach that employs the Resistance-Curve concept, in order to predict fatigue endurances of welded components, with different tensile strengths of the base metal. The Resistance-Curve method compares the total driving force applied to a crack with its threshold for propagation, both defined as a function of crack length. The former depends on load scheme and weld geometry and it can be obtained from finite element analyses, while the second is inherently related to weld resistance. Results obtained herein showed that threshold curve shape is changed when static strength of the base material is modified. Consequently, its interaction with the driving force differed, giving raise to different fatigue endurances for various values of the tensile strength. However, this effect is only likely to be leveraged, provided that the initial crack length is small enough. In real welded structures, the presence of defects demands longer initial crack lengths to be used in calculations, at which the benefit of enhanced strength is minimised or even inverted. Moreover, at these lengths, the growing process is mainly controlled by weld geometry and long crack propagation threshold, whereas local properties become less important in fatigue limit prediction.
\end{abstract}

\section{Introduction}

In the last decades, industries have invested much effort and time in developing safe structures with minimum costs. Advances in materials and inspecting techniques have led to lighter structures that safely withstand design loads, including either static or cyclic stresses. Among these materials, high strength steels (HSS) with yield strength over $600 \mathrm{MPa}$ have particularly caught the attentions of companies and researchers.

It is normally believed, that tensile strength of base material does not have an influence on final fatigue resistance of welded components [1-5]. On the other hand, short crack behaviour is known to determine the fatigue limit of metals, which is therefore affected by microstructure [6-8]. Furthermore, fusion welding processes alter base material (BM) microstructures and may lead to harder regions, presenting local properties with enhanced plain fatigue limit in the heat affected zone (HAZ). Considering these facts, it can be thought that an increase in the tensile strength of the BM would lead to improved fatigue resistance. However, in this analysis, initial crack length and overall weld geometry is not being considered. As-welded joints are likely to present defects that range in size from some $\mu \mathrm{m}$ to 150 $\mu \mathrm{m}$ or even more [1-3]. The effect of residual stresses, inhomogeneity and stress concentrators that usually appear in welds (slag inclusions, undercuts, overlaps, among others) essentially overwhelm the influence of other factors, such as the static strength of the main plate. Therefore, enhancing this mechanical parameter may not improve fatigue strength of the joint. This statement can be questioned by observing limitation of material yield strength in current fatigue design documents, to stress up to ca. $960 \mathrm{MPa}[4,9,10]$. Although this is mainly related to a lack of experimental data for ultra high-strength steels, subject is still at open debate, and much work is needed for better understanding of the damaging mechanisms and controlling variables in this kind of materials.

\section{Methodology}

Methodology employed in the present research to predict fatigue strength of welded components is thoroughly described in previous publications from the authors [1113]. It is based on the resistance curve method that compares the total driving force applied to a crack with its threshold for propagation, resulting in the effective driving force. The latter is the energy necessary for crack growth.

The applied driving force depends on load scheme, geometry and crack length. It can be properly described by the applied stress intensity factor range, $\Delta \mathrm{K}$. Likewise, crack propagation threshold, $\Delta \mathrm{K}_{\mathrm{th}}$, is a function of crack size and in the present approach it includes the short crack regime. Relationship between 
these quantities can be expressed as a modified Paris Law, like Eq. (1).

$$
d a / d N=C\left(\Delta K-\Delta K_{t h}\right)^{m}
$$

where $C$ and $m$ are constants that depend on material and environment. Note that in the case of fatigue limit assessment the value adopted by constants in Eq. (1) is irrelevant, since for $d a / d N$ approaching to zero only equality between $\Delta \mathrm{K}$ and $\Delta \mathrm{K}_{\mathrm{th}}$ defines the critical stress range.

Chapetti proposed a method to calculate crack propagation threshold [14] based on location $d$ of the strongest microstructural barrier, which defines a microstructural threshold for short crack propagation. This variable can be expressed as follows:

$$
\Delta K_{d R}=Y \Delta \sigma_{e R}(\pi d)^{1 / 2}
$$

where $Y$ is a geometrical factor and $\Delta \sigma_{\mathrm{eR}}$ is the plain fatigue limit, described as the nominal stress range below which cracks do not propagate in a smooth sample. Since it depends on the stress ratio, $R$, the microstructural fatigue threshold also does. The value of microstructural barrier, $d$, is usually determined by ferrite grain size and bainite or martensite lath length $[8$, 14].

In the long crack range, threshold adopts a constant value, represented by $\Delta K_{\text {thR }}$, for a given stress ratio $R$. Difference between this mechanical threshold for long cracks and microstructural fatigue threshold, $\Delta \mathrm{K}_{\mathrm{dR}}$, gives $\Delta \mathrm{K}_{\mathrm{CR}}$, according to Eq. (3).

$$
\Delta K_{C R}=\Delta K_{t h R}-\Delta K_{d R}
$$

where $\Delta \mathrm{K}_{\mathrm{CR}}$ is constant and depends on the stress ratio $R$. In order to connect $\Delta \mathrm{K}_{\mathrm{dR}}$ to $\Delta \mathrm{K}_{\mathrm{thR}}$ a transition region should be defined. Chapetti suggested [14] that the development of the extrinsic component $\Delta \mathrm{K}_{\mathrm{C}}$ can be calculated with Eq. (4).

$$
\Delta K_{C}=\Delta K_{C R}\left(1-e^{-k(a-d)}\right)
$$

where $k$ is a material constant that controls the shape of the transition zone for each stress ratio, and $a$ is the crack length in $\mathrm{mm}$, measured from the free surface.

Finally, the shape of a single threshold curve that describes the resistance of a material to crack growth can be described by Eq. (5).

$$
\Delta K_{t h}=\Delta K_{d R}+\Delta K_{C}=Y \Delta \sigma_{t h}(\pi a)^{1 / 2}
$$

Replacing Eq. (3) and (4) into (5), the following form of the threshold curve is obtained:

$$
\Delta K_{t h}=\Delta K_{d R}+\left(\Delta K_{t h R}-\Delta K_{d R}\right)\left(1-e^{-k(a-d)}\right)
$$

which is valid for $a \geq d$.

It was found that that the value of $k$ in Eq. (7) gives a threshold for fatigue crack propagation that correlates well with experimental data [14].

$$
k=\Delta K_{d R} /\left[4 d\left(\Delta K_{t h R}-\Delta K_{d R}\right)\right]
$$

\section{Finite element model}

A finite element software [15] was employed to simulate an $8 \mathrm{~mm}$ butt-welded joint, having a reinforcement angle, $\alpha$, of $147^{\circ}$. Two-dimensional linear elastic model was assumed and symmetry was considered in order to improve simulation performance. Figure 1 shows symmetric model and it schematically displays load configuration, boundary conditions and overall geometry. Four point bending was considered. Minor and major span are represented by $s$ and $L$, respectively, $t$ is the plate thickness and $P$ is the applied load. All these variables define the maximum nominal stress on the surface that is used in the following calculations.

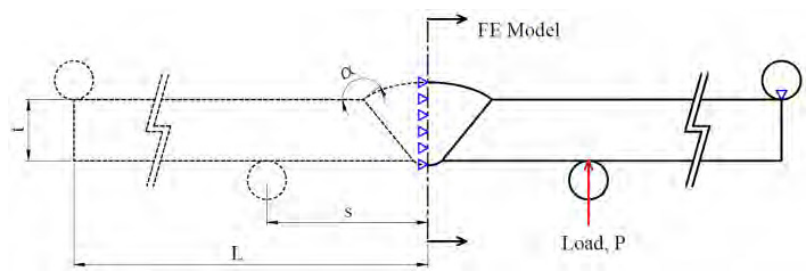

Fig. 1. Geometry, load configuration and boundary conditions of the finite element model. $t$ is the plate thickness, $\alpha$ is the reinforcement angle, $s$ is half the minor span, $L$ is half the major span and $P$ is the applied load.

Stress intensity factors were obtained following software procedure for fracture mechanic simulations [15]. Cracks were introduced as "seam cracks" growing from the weld toe and the maximum energy release criterion was selected to determine the crack propagation direction. Concentric circular partitions were done from the crack tip, and the area defined by the first circle was considered to be the crack front, which will later be computed as the first contour integral. Mesh was constructed with 6-node quadratic plane strain triangles in the crack front, which use a modified second-order interpolation, whereas 8-node biquadratic plane strain quadrilateral elements were assigned to the rest of the mesh. The software converts the elements in the crack front to collapsed quadrilateral elements. In order to improve accuracy, a square root singularity is recommended to be assigned to the crack tip, which constrains the collapsed nodes to move together.

It must be mentioned, that the analysis was purely geometric and residual stresses resulting from the welding process were not considered at this first instance.

Stress intensity factor depends on weld geometry, crack length and applied remote stress. Having defined the weld detail and load in the bending test, their values can be obtained for different crack lengths by means of the finite element analysis described previously. This procedure was repeated for 17 different crack lengths ranging from $20 \mu \mathrm{m}$ to $2.5 \mathrm{~mm}$, following a simplified path perpendicular to the plate surface, i.e. normal to the maximum nominal stress. Step size was varied from 25 $\mu \mathrm{m}$ to $100 \mu \mathrm{m}$ in the first millimetre, in order to obtain an accurate profile in the short crack range. For larger crack lengths, $0.5 \mathrm{~mm}$ was selected.

Having calculated $\Delta \mathrm{K}$ vs. $a$ for a predefined $\Delta \sigma$ and a propagation threshold curve, $\Delta \mathrm{K}_{\mathrm{th}}$, fatigue limit can be 
Table 1. Mechanical properties and important parameters for the model. $R=0.1$.

\begin{tabular}{|c|c|c|c|c|c|c|c|c|c|}
\hline & $\sigma_{\mathrm{vs} 0.2}[\mathrm{MPa}]$ & $\sigma_{\text {UTS }}[\mathrm{MPa}]$ & \multicolumn{2}{|c|}{$\Delta \mathbf{K}_{\mathrm{thR}}[\mathrm{MPa} \sqrt{ } \mathrm{m}]$} & \multicolumn{2}{|c|}{$\Delta \sigma_{\mathrm{eR}}[\mathrm{MPa}]$} & $d[\mu \mathrm{m}]$ & \multicolumn{2}{|c|}{$\mathrm{H}_{\mathrm{V} 10}$} \\
\hline Zone & $\mathrm{BM}$ & $\mathrm{BM}$ & $\mathrm{BM}$ & HAZ & $\mathrm{BM}$ & HAZ & HAZ & $\mathrm{BM}$ & HAZ \\
\hline A36 [12, 13] & 286 & 472 & 7.03 & - & - & 360 & 28 & 180 & 360 \\
\hline S960MC & 990 & 1030 & $6.25 *$ & $5.8^{*}$ & 550 & $650^{*}$ & 20 & 320 & 380 \\
\hline
\end{tabular}

determined by equalising Eq. (1) to zero. There is a value of $\Delta \sigma$ for which both curves touches at a single point. This is the critical stress or fatigue limit of the configuration, and the contact point between the two curves is the non-propagating crack length.

\section{Materials}

Materials used in the present analysis are a structural steel, A36, and a high strength steel S960MC, in accordance with standards ASTM A36 [16] and EN 10149-2 [17], respectively. Welds were manufactured with gas metal arc welding (GMAW) in the structural steel and laser hybrid welding (LHW) in the HSS.

Mechanical properties and important variables for the model are displayed in Table 1. In the HSS, some parameters had to be estimated as described below. They are indicated with an asterisk in Table 1. It is also shown the relevant zone associated to each parameter. Hardness values were measured at the HAZ, close to the weld toe, where the cracks are likely to grow. Similarly, value of $d$ was determined in the same region as the average size of martensite laths, in accordance with previous studies [8, 14].

The plain fatigue limit was estimated with the properties of the HAZ. Assuming that fatigue limit is proportional to hardness, ratio of HV between HAZ and $\mathrm{BM}$ approximates the increase in the fatigue limit in the former. Since the average HV in the HAZ is around 380 $\mathrm{HV}_{10}$, and $320 \mathrm{HV}_{10}$ in the $\mathrm{BM}$, and the experimental fatigue limit at $R=0.1$ in the $\mathrm{BM}$ is $\Delta \sigma_{\mathrm{eR}}=550 \mathrm{MPa}$ (see Table 1), then $\Delta \sigma_{\mathrm{eR}} \approx 650 \mathrm{MPa}$ in the HAZ.

Long crack propagation threshold of $\mathrm{S} 960 \mathrm{MC}$ at $R=$ 0.1 was obtained from Figure 2, by means of the ultimate tensile strength of the BM, giving $6.25 \mathrm{MPa} \sqrt{ }$.

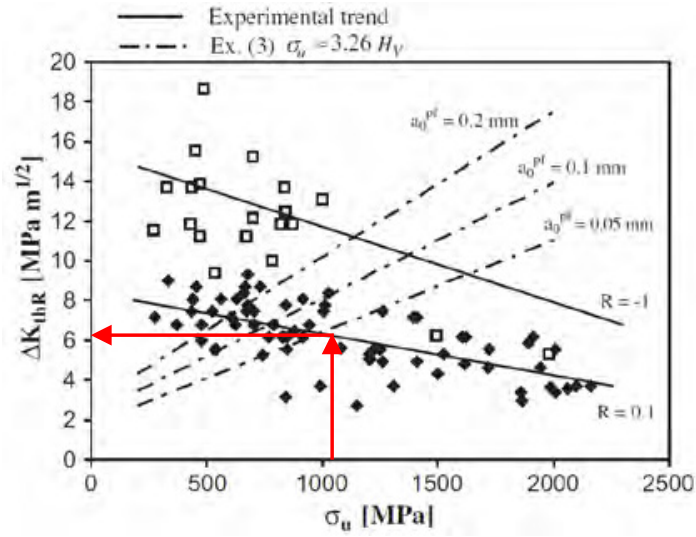

Fig. 2. Variation of long crack propagation threshold with the static strength of material $[18,19]$.

Due to the geometry of the weld pool and the final bead appearance, it can happen in LHW that the crack initiates in the HAZ and propagates mainly into that region. Therefore, the long crack propagation threshold should also be corrected accordingly with HAZ mechanical properties. By considering the well-known relation $\sigma_{\mathrm{UTS}}=3.26 \mathrm{H}_{\mathrm{V}}$, the ultimate tensile strength in the HAZ of S960MC can be estimated. After this, Figure 2 can be used to estimate the long crack propagation threshold in the HAZ, giving a value of $5.8 \mathrm{MPa} \sqrt{\mathrm{m}}$.

\section{Results}

At this first stage of the assessment, the weld geometry was simplified in accordance with former studies [13]. A butt-weld with toe radius equal to zero and reinforcement angle equal to $147^{\circ}$ was used in the FE model. This procedure allows comparing previous results on structural steel [13] with the present analysis on high strength steel.

In order to compare results when variables are changed, a reference case must be assumed. Due to the reasons given before, the HAZ properties best describe the crack growing process in the $\mathrm{S} 960 \mathrm{MC}$ weld. Then, $\Delta \sigma_{\mathrm{eR}}=650 \mathrm{MPa}, d=20 \mu \mathrm{m}$ and $\Delta \mathrm{K}_{\mathrm{thR}}=5.8 \mathrm{MPa} \sqrt{\mathrm{m}}$ are the reference values. Under these circumstances, prediction for two different initial crack lengths is shown in Figure 3. It is important to mention, that values adopted for $\Delta \sigma_{\mathrm{eR}}, d$ and $\Delta \mathrm{K}_{\mathrm{thR}}$ determine a flat threshold curve with almost no noticeable transition at low crack lengths. This implies that the fatigue limit depends mainly on the long crack propagation threshold, which is constant, and the geometry of the weld, given by the applied stress intensity factor curve.

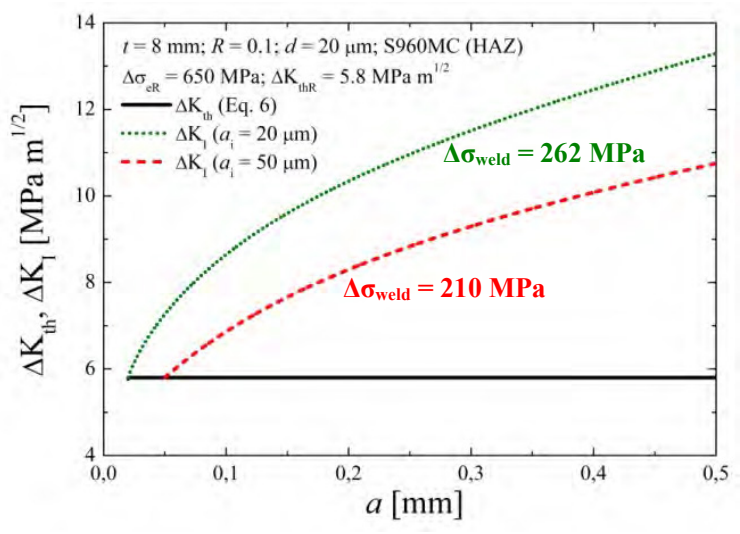

Fig. 3. Fatigue limit prediction in $\mathrm{S} 960 \mathrm{MC}(\mathrm{HAZ})$, for $\Delta \sigma_{\mathrm{eR}}=$ $650 \mathrm{MPa}, d=20 \mu \mathrm{m}$ and $\Delta \mathrm{K}_{\mathrm{thR}}=5.8 \mathrm{MPa} \sqrt{\mathrm{m}}$, at two different initial crack lengths: 20 and $50 \mu \mathrm{m} . R=0.1$ and $t=8 \mathrm{~mm}$.

It can be argued that determination of the fatigue limit in the HAZ from hardness values is very empirical. Likewise, long crack propagation threshold from Figure 2 obeys an empirical relation. In order to assess the effect of each variable that affects the threshold curve and estimate an error when using empirical deductions, sensitivity analyses were conducted. Value of $d$ was 
allowed to vary from $10 \mu \mathrm{m}$ to $20 \mu \mathrm{m}$, plain fatigue limit from $550(\mathrm{BM})$ to $650 \mathrm{MPa}$ (HAZ), and long crack propagation threshold from 5.8 (HAZ) to $6.25 \mathrm{MPa} \sqrt{\mathrm{m}}_{\mathrm{m}}$ (BM).

\subsection{Effect of the strongest microstructural barrier, $d$.}

Figure 4 illustrates variations the threshold curve for three values of $d$. It can be seen that shorter microstructural barriers give lower fatigue limits in the welds, when initial crack length is small enough to be affected by these changes. Note that plateau is practically developed in all cases for crack lengths above $0.1 \mathrm{~mm}$, where the long crack propagation threshold controls the growing process.

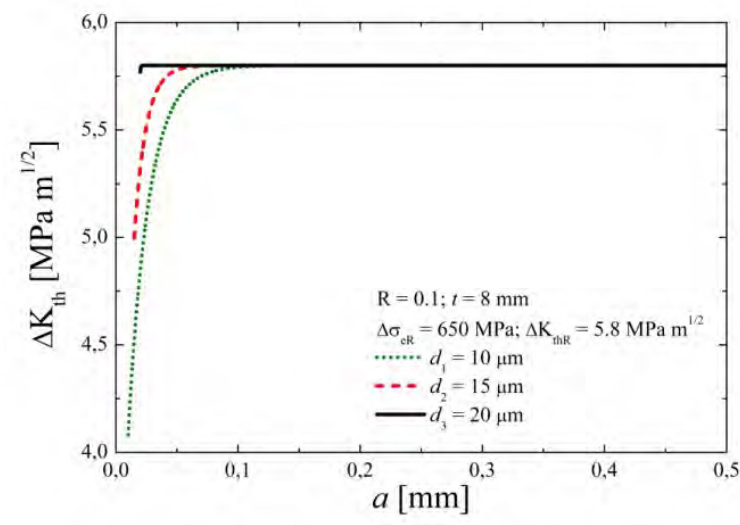

Fig. 4. Change in threshold curve with variation of the strongest microstructural barrier.

\subsection{Effect of the plain fatigue limit, $\Delta \sigma_{e R}$.}

The effect of the plain fatigue limit of the material at the toe region can be analysed, keeping $d$ and $\Delta \mathrm{K}_{\text {thR }}$ constant. This behaviour can be seen in Figure 5, in which a minimum plain fatigue limit corresponding to the BM (experimentally determined) was employed. The highest value of $650 \mathrm{MPa}$ was calculated by relating hardness with fatigue strength values.

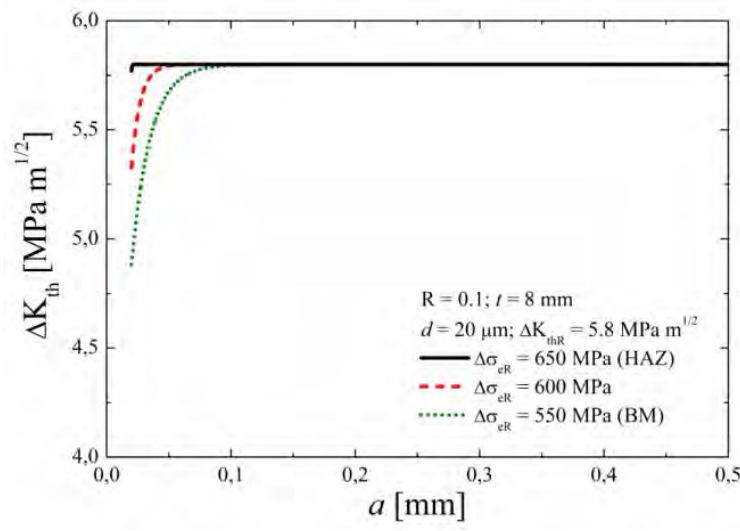

Fig. 5. Change in threshold curve with variation of the plain fatigue limit at the toe region.

\subsection{Effect of the long crack propagation threshold, $\Delta K_{t h R}$.}

Finally, the change in the threshold curve with variation in $\Delta \mathrm{K}_{\mathrm{thR}}$ can be assessed. This is represented in Figure 6, where an increase in the plateau ordinate can be related to a higher $\Delta \mathrm{K}_{\mathrm{thR}}$, as it was expected.

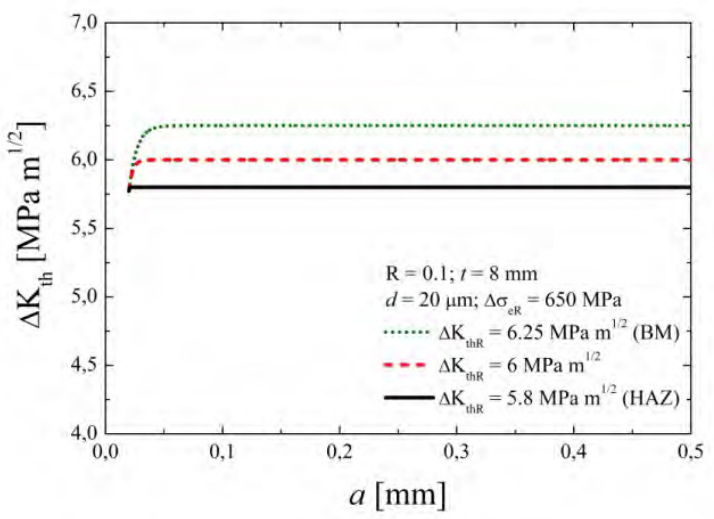

Fig. 6. Change in threshold curve with variation of the long crack propagation threshold.

\subsection{Prediction of the fatigue limit of welded joints.}

Results showed in Figures 4 to 6 can be used to predict the fatigue limit in each case, for the weld under consideration, and for different initial crack lengths. This is achieved by comparing threshold curves with the applied stress intensity factor curve, as shown in Figure 3. Figure 7 displays a Kitagawa-Takahashi-like chart, showing the effect of the strongest microstructural barrier, $d$, on the predicted fatigue strength of the weld. It is evident that $d$ only influences results when $a_{\mathrm{i}}<50$ $\mu \mathrm{m}$, a value that is very short to be used in real weld calculations. Additionally, it can be seen that long crack propagation threshold defines the fatigue limit for longer initial crack length.

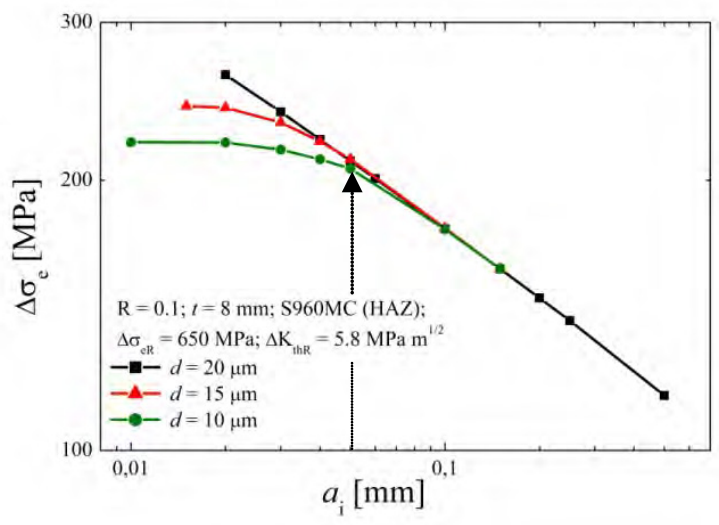

Fig. 7. K-T plot, showing the effect of the strongest microstructural barrier, $d$, on the fatigue strength of the HSS joint.

Figure 8 displays the K-T diagram when plain fatigue limit is varied. Results are similar as before, and the influence of this variable is only noticeable when $a_{\mathrm{i}}<50$ $\mu \mathrm{m}$. 
A similar procedure can be done with $\Delta \mathrm{K}_{\mathrm{thR}}$, when $\Delta \sigma_{\mathrm{eR}}=650 \mathrm{MPa}$ and $d=20 \mu \mathrm{m}$ are held constant. This situation measures the influence of variation in the long crack propagation threshold, on fatigue strength prediction. Figure 9 illustrates the case. It is important to note that difference in results is little, and it presents a maximum discrepancy close to $a_{\mathrm{i}}=50 \mu \mathrm{m}$, above which it starts to decrease with crack length. It must be highlighted, that in the log-log scale, the three curves tend to be parallel with increasing initial crack lengths.

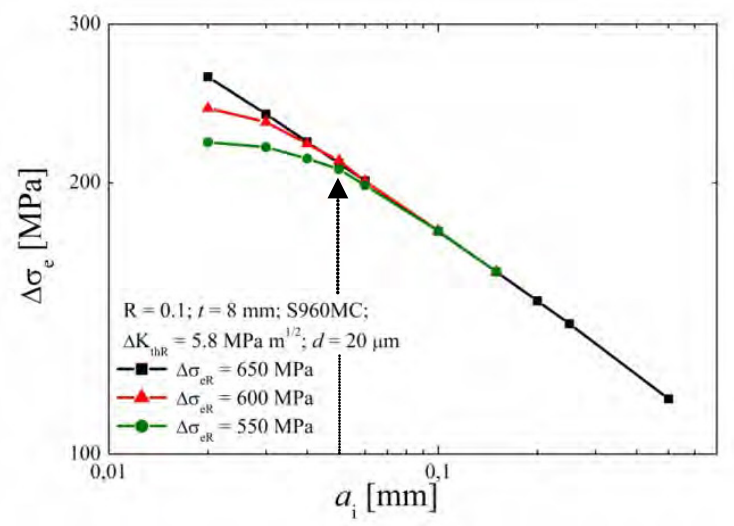

Fig. 8. K-T plot, showing the effect of the plain fatigue limit at the toe region, $\Delta \sigma_{\mathrm{eR}}$, on the fatigue strength of the HSS joint.

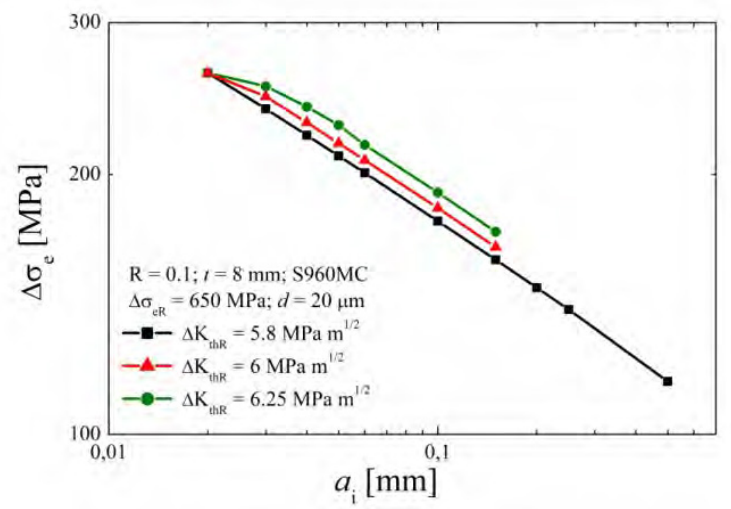

Fig. 9. K-T plot, showing the effect of long crack propagation threshold, $\Delta \mathrm{K}_{\mathrm{thR}}$, on the fatigue strength of the HSS joint.

\section{Analyses and discussions}

An increase in the BM strength reduces the long crack propagation threshold, as it is shown in Figure 2. At the same time, a reduction in $\Delta \mathrm{K}_{\mathrm{thR}}$ results in slightly lower fatigue limits, depending on the initial crack length, as it is depicted in Figure 6 and 9. Regarding initial crack length, it is important to consider that codes and standards usually recommend at least $50 \mu \mathrm{m}$ for integration. Common values are around 100 and $150 \mu \mathrm{m}$ $[4,9,20-22]$. Only in the case of high quality welds, smaller lengths can be allowed.

On the other hand, an increase in tensile strength is usually accompanied by an enhanced plain fatigue limit, which consequently leads to a higher $\Delta \mathrm{K}_{\mathrm{dR}}$, in accordance with Eq. (2). This is reflected in curves from Figures 4 to 6 , where stronger materials present a sharp transition in the threshold curve, with a squared appearance. Consequently, fatigue limit of the welded component is less affected by plain fatigue limit and is mainly defined by weld geometry (applied stress intensity factor curve) and long crack propagation threshold. This is evident in Figures 7 to 9 for S960MC joints containing normal flaws $\left(a_{\mathrm{i}} \geq 50 \mu \mathrm{m}\right)$.

This result is very important for assessing fatigue behaviour of welded components, since the variables that control the damaging mechanisms can be isolated and improved (if possible).

In order to clarify these concepts, three representative welds are considered. The first corresponds to the reference case previously described $\left(\Delta \sigma_{\mathrm{eR}}=650 \mathrm{MPa}, d\right.$ $=20 \mu \mathrm{m}$ and $\left.\Delta \mathrm{K}_{\mathrm{thR}}=5.8 \mathrm{MPa} \sqrt{\mathrm{m}}\right)$, associated to S960MC HAZ. The second option is the same weld modelled with the properties of the BM $\left(\Delta \sigma_{\mathrm{eR}}=550\right.$ $\mathrm{MPa}, d=20 \mu \mathrm{m}$ and $\left.\Delta \mathrm{K}_{\mathrm{thR}}=6.25 \mathrm{MPa} \sqrt{\mathrm{m}}\right)$. Finally, a weld made of A36 was considered, with local properties corresponding to the $\mathrm{HAZ}\left(\Delta \sigma_{\mathrm{eR}}=360 \mathrm{MPa}\right.$ and $d=28$ $\mu \mathrm{m})$ and $\Delta \mathrm{K}_{\mathrm{thR}}=7.03 \mathrm{MPa} \sqrt{\mathrm{m}}$ of the $\mathrm{BM}[12,13]$. Predicted fatigue strengths of the joints are displayed in Figure 10, as a function of the initial crack length.

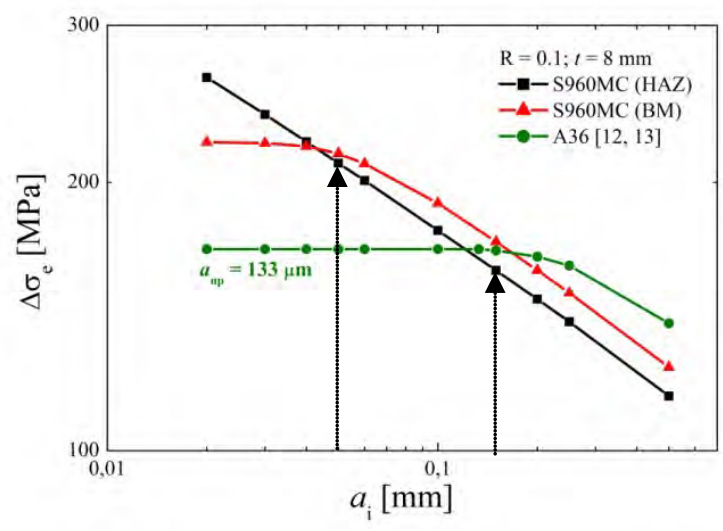

Fig. 10. K-T plot showing the fatigue strength of welds as a function of initial crack length, for three distinct cases.

If welds are performed under high quality control procedures, it is reasonable to assume an initial crack length equal to $50 \mu \mathrm{m}$. Under this assumption, increasing the strength of the BM leads to a higher fatigue strength of the weld.

Since the non-propagating crack length that determines the fatigue limit in the A36 steel joint is around $130 \mu \mathrm{m}$, then comparison between materials should be done at a longer initial crack length. At the same time, joints in the as-welded condition with scarce quality controls are usually related to longer initial crack length. By assuming an average value of $150 \mu \mathrm{m}$, based on recommendations in design documents [20-22], it can be seen in Figure 10 that trend is inverted and HSS welds start to become weaker than their structural steel counterparts. Particularly, for $a_{\mathrm{i}}=150 \mu \mathrm{m}$ HSS weld fatigue limit is around $160 \mathrm{MPa}$, whereas that of A36 weld is approximately $168 \mathrm{MPa}$.

In spite of this, differences between curves are not significant above $100 \mu \mathrm{m}$, as is depicted in Figure 11 . Below this value, the effect of static strength of BM may be considered in design. 


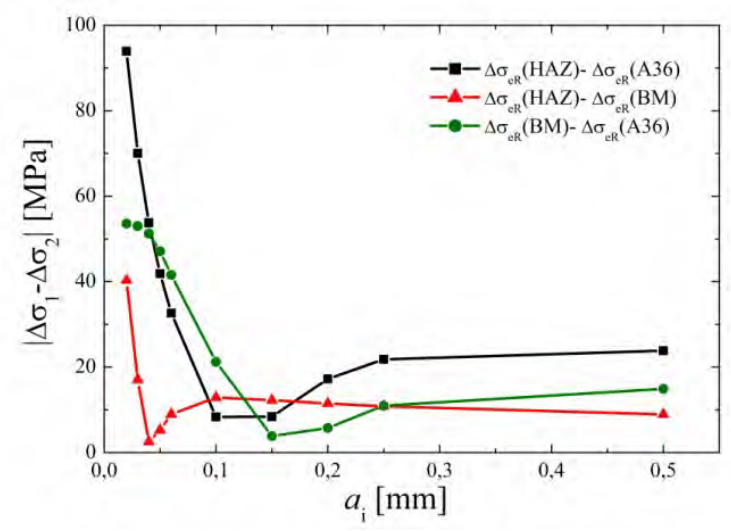

Fig. 11. Absolute differences between curves in Figure 10.

Technically, these results imply that low or medium quality joints, where flaws are likely to be found at the toe, might not experience any benefit from stronger materials, whereas high quality welds (for example, FAT values above 100) may be more susceptible to changes in BM strength. It can be further deduced that joints presenting improved weld profiles by grinding or TIGdressing, may also experience the benefit from enhanced strength of the BM, as it was observed in different studies [2, 3, 23, 24]. These improvement techniques not only re-shape weld profile, but also reduce the amount of defects at the weld toe [25]. Therefore, smaller initial flaw sizes can be assumed.

A final comment can be done in relation to slope in the log-log scale at long crack lengths. Figures 7 to 10 show that at long initial crack length, slope in the K-T plot is constant. This implies that the fatigue limit of the weld depends mainly on the long crack propagation threshold (which is constant) and the geometry of the joint. Therefore, relation between fatigue strength of the weld and initial crack length can be deduced and it is generally described by Eq. (8).

$$
\Delta \sigma_{e R}=\Delta K_{t h R} /\left[Y\left(\pi a_{i}\right)^{n}\right]=A \cdot a_{i}^{-n}
$$

where $\mathrm{A}$ is a constant that depends on geometry and long crack propagation threshold, and $n$ is the exponent that also depends on the geometry of the weld and loading scheme (i.e. bending). Figure 12 illustrates results for the reference case (S960MC HAZ), together with the fitting curve. It was found that a power relation best fit results, in accordance with Eq. (8), presenting an exponent $n$ around 0.25 . This value can be analysed by calculating the derivative of the applied stress intensity factor curve. Figure 13 depicts the latter in the log-log scale, and the corresponding slope for the whole range of crack lengths. It can be seen in this figure, that the slope is approximately 0.25 for crack lengths up to $0.3 \mathrm{~mm}$. Beyond this value, the slope starts to increase markedly.

\section{Conclusions}

Resistance curve concept was employed to determine the influence of the ultimate tensile strength on the fatigue behaviour of welded components. It was shown that an increase in the static strength of the BM enhances the value of $\Delta \mathrm{K}_{\mathrm{dR}}$ and reduces $\Delta \mathrm{K}_{\mathrm{thR}}$, generating a threshold curve that presents a sharp transition above the value of $d$. Under these circumstances, fatigue threshold of the weld becomes less dependent on the plain fatigue limit, $\Delta \sigma_{\mathrm{eR}}$, and it is increasingly defined by the long crack propagation threshold, $\Delta \mathrm{K}_{\text {thR }}$. Since the applied stress intensity factor curve depends only on geometry and loading conditions and it is not altered by changes in BM properties, fatigue strength of the welded joint is principally defined by the overall geometry and $\Delta \mathrm{K}_{\text {thR }}$.

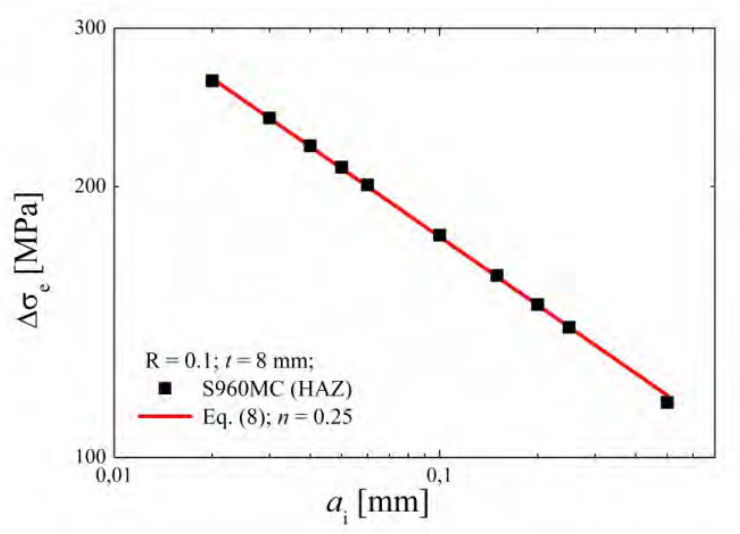

Fig. 12. Fatigue strength of S960MC (HAZ), and power fitting.

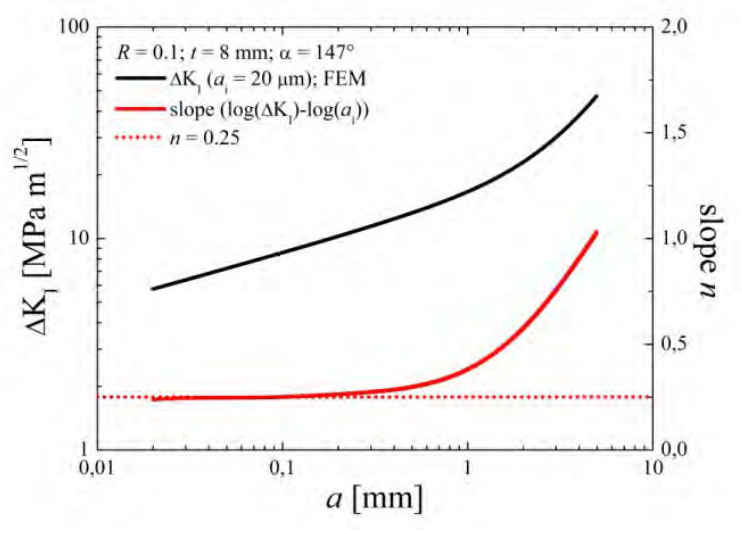

Fig. 13. Slope $n$ of the $\log \Delta \mathrm{K}_{\mathrm{I}} \mathrm{vs.} \log a$ plot.

Methodology additionally revealed that either a decrease in $\Delta \sigma_{\mathrm{eR}}$ or a shorter microstructural barrier, $d$, reduced the fatigue strength of the weld, provided that the initial crack length is sufficiently small $\left(a_{\mathrm{i}}<50 \mu \mathrm{m}\right)$. However, in the presence of larger flaws, their influence becomes less important. Since the natural presence of defects in normal welds demands a larger crack length to be assumed as the initial defect, then, the possible improvement in fatigue behaviour by employing stronger materials vanishes accordingly. Furthermore, the benefit of altering $\Delta \mathrm{K}_{\text {thR }}$ by modifying the static strength is small.

The historical believe that fatigue limit of welded components do not change with yield strength is based on experimental observations generally made on aswelded joints. Defects normally found in these samples greatly affect fatigue behaviour as was demonstrated in previous publications. Then, the influence of static properties is overwhelmed by other parameters, such as undercut depth or underfill depth. This implies that weld 
profile improvement methods (TIG-dressing and grinding) that remove undesired defects from the toe, can experience the benefits of employing HSS in fatigue loaded welds, as it is mentioned in literature.

For the particular case presented in this work, initial crack lengths as short as $0.1 \mathrm{~mm}$ are enough to hide any benefit from elevated static strength. For shorter crack lengths, the presence of non-propagating crack length in the former material cause a strong influence of the static strength. However, no standard, code or recommendation allows integration from such small flaws in normal situations.

In summary, methodology presented in the present work, although applied to particular steels, showed its usefulness for analysing fatigue limit of welded components and its dependence on certain variables. The influence of the most important parameters can be assessed in order to have a better insight of the damaging phenomenon. Control over these variables may contribute to a better performance of welded components under cyclic loading.

Authors wish to express their gratitude to the funding provided by CONICET (Consejo Nacional de Investigaciones Científicas y Técnicas), and by Agencia Nacional de Promoción Científica Tecnológica, Argentina (PICT 2013 Nro.0110). Support was also provided by the K-Project Network of Excellence for Metal JOINing which is fostered in the frame of COMET - Competence Centers for Excellent Technologies by BMWFW, BMVIT, FFG, Land Oberösterreich, Land Steiermark, Land Tirol and SFG. The programme COMET is handled by FFG.

\section{References}

1. T.R. Gurney, Fatigue of welded structures, $2^{\text {nd }}$ ed., London: Cambridge UP (1979)

2. S.J. Maddox, Fatigue strength of welded structures, $2^{\text {nd }}$ ed., Abington, Cambridge (1991)

3. D. Radaj, Design and analysis of fatigue resistant welded structures, Abington Publishing (1990)

4. A.F. Hobbacher, Recommendations for Fatigue Design of Welded Joints and Components, $2^{\text {nd }}$ ed., Springer International Publishing (2016)

5. EN 1993-1-9:2010-12, Eurocode 3: Design and construction of steel components - Part 1-9: Fatigue.

6. D. Taylor, J.F. Knott, Fat. Eng. Mat. Struct. 4(2), 147-155 (1981)

7. J. Lankford, Fat. Eng. Mat. Struct. 8(2), 161-175 (1985)

8. K.J. Miller, Fat. Eng. Mat. Struct. 16(9), 931-939 (1993)

9. British Standard, BS 7608-2014: Guide to fatigue design and assessment of steel products, BSI Standards Limited (2014)

10. Det Norske Veritas As, DNVGL-RP-C203: Recommended Practice-Fatigue Design of Offshore Steel Structures (2016)
11. M.D. Chapetti, J. Belmonte, T. Tagawa, T. Miyata, Sci. Tech. Weld. Join. 9(5), 430-438 (2004)

12. M.D. Chapetti, L.F. Jaureguizahar, Int. J. Fatigue, 43, 43-53 (2012)

13. C. Steimbreger, M.D. Chapetti, Int. J. Fatigue, 105, 296-304 (2017)

14. M.D. Chapetti, Int. J. Fatigue, 25(12), 1319-26 (2003)

15. Dassault Systèmes, Simulia. Abaqus 6.13 User manual, Providence, RI, USA (2013)

16. ASTM A36 / A36M-14, Standard Specification for Carbon Structural Steel, ASTM International, West Conshohocken, PA (2014)

17. British Standard, BS EN 10149-2:2013, Hot rolled flat products made of high yield strength steels for cold forming. Technical delivery conditions for thermomechanically rolled steels, BSI Standards Limited (2013)

18. M. Jono (Ed.), Data book on the fatigue crack growth rates of metallic materials, Society of Materials Science, Japan (JSMS) (1983)

19. M.D. Chapetti, Int. J. Fatigue, 33, 833-841 (2011)

20. British Standard, BS 7910:2013+A1:2015: Guide to methods for assessing the acceptability of flaws in metallic structures, BSI Standards Limited (2015)

21. Det Norske Veritas As, DNVGL-RP-C210: Recommended Practice-Probabilistic methods for planning of inspection for fatigue cracks in offshore structures (2016)

22. B. Jonsson, G. Dobmann, A.F. Hobbacher, M. Kassner, G. Marquis, IIW Guidelines on weld quality in relationship to fatigue strength, IIW Collection, Springer International Publishing, Switzerland (2016)

23. T. Dahle, Int. J. Fatigue, 20(9), 677-681 (1998)

24. H.C. Yildirim, Int. J. Fatigue, 79, 36-45 (2015)

25. P.J. Haagensen, S.J. Maddox, IIW Recommendatons on methods for improving the fatigue strength of welded joints (IIW-2142-10), Woodhead Publishing Limited, Cambridge, UK (2013) 